\title{
Intraspecific Morphological Variation in Two Common Marine Fish Spe- cies from South Africa
}

\author{
Eric Mattson and Mark C. Belk ${ }^{*}$
}

Department of Biology, 401 WIDB, Brigham Young University, Provo, Utah, USA 84602

\begin{abstract}
Intraspecific morphological variation in fish is typically associated with sexual dimorphism, or one of three common environmental gradients: variation in intensity of predation, variation in water velocity, or variation in feeding niche. The preponderance of examples of environment-associated morphological variation within fish species has been documented in freshwater systems. It is not clear whether environment-associated intraspecific morphological variation is less common in marine fishes or whether there has just been a lack of investigation. We used geometric morphometric analysis to quantify shape variation in two species of South African marine fish commonly harvested for human consumption, Pterogymnus laniarius (panga), and Argyrosomus inodorus (silver kob). Neither species exhibited significant sexual dimorphism, but both species exhibited significant intraspecific morphological variation. This variation appears consistent with patterns expected from variation along the benthic-pelagic feeding niche continuum.
\end{abstract}

Keywords: Argyrosomus inodorus; feeding niche, geometric morphometrics; intraspecific variation; marine fish; morphology; Pterogymnus laniarius.

\section{INTRODUCTION}

Fishes exhibit a wide range of intraspecific morphological variation that has been shown to be ecologically and evolutionarily important [1, 2]. Many fishes exhibit sexual dimorphism [3, 4]. In addition, intraspecific morphological variation has been observed in a variety of fish species associated with variation in habitat, diet, and other factors [5-10]. In many cases this variation has been shown to be heritable. Formation of different morphologies within the same species that specialize in different uses of resources is thought to be a major force in the evolution of new species [1].

Most non-sexual intraspecific morphological variation in fish can be associated with separation along one of three common environmental gradients. First, the presence of predators has a strong effect on morphology of fishes. For example, western mosquitofish (Gambusia affinis) from habitats with high intensities of predation have a larger caudal region and shallower head/body region than mosquitofish from habitats with lower intensities of predation [11]. These changes in morphology allow higher burst swimming speeds which aids in avoiding predation. In Eurasian perch (Perca fluviatilis), high-intensity predation is associated with a deeper, downward bent body shape, while perch in areas with low predation intensity have a comparatively shallower, upward bent body shape [12]. The deeper body shape decreases mortality from gape-limited predators. Second, water velocity affects morphology of fishes [13]. For example, brook charr (Salvelinus fontinalis) inhabiting high-velocity water have larger caudal fins and more slender bodies than

*Address correspondence to this author at the Department of Biology, 401 WIDB, Brigham Young University, Provo, Utah, USA 84602;

Tel: 801-422-4154; Fax: 801-422-0090; Email: mark_belk@byu.edu those inhabiting low velocity water [14]. The slender body shape decreases drag and the larger caudal fins increase thrust, helping the fish to cope with the higher water velocities. The third, and possibly most commonly studied, pattern of environmental variation corresponds to the benthicpelagic feeding niche continuum. This phenomenon of having benthic and pelagic forms coexisting has been documented many times in lacustrine environments $[1,15,16]$. Benthic and pelagic morphologies within the same species are present in systems as diverse as whitefish (Coregonus lavaretus) [17], brook charr (Salvelinus fontinalis) [18], orangespotted sunfish (Lepomis humilis) [19], and threespine sticklebacks (Gasterosteus aculeatus) [20]. This variation is characterized by the position of the mouth and the size and shape of the body. Mouths are usually downturned in benthic feeders, terminally placed in pelagic feeders, and upturned in surface feeders [21, 22]. Benthic morphs usually display a more robust body shape with a broad rounded snout, whereas pelagic morphs usually exhibit a more fusiform slender body $[23,24]$. Individuals that feed on the benthos benefit from increased feeding efficiency associated with the broad rounded snouts and downturned mouths [1, 21].

Morphological variation in fish along all three of these environmental gradients has mainly been observed in isolated, relatively depauperate, freshwater systems. Such patterns have been poorly documented in marine systems. A recent search of the literature on non-sexual intraspecific morphometric variation in fishes yielded forty-five examples documented in freshwater fishes, but only three examples in marine fishes. All three of these examples in marine fishes occurred in populations separated by large geographic distance, and none showed different morphologies occurring in sympatry. This preponderance of freshwater examples may be the result of fundamental differences between freshwater 


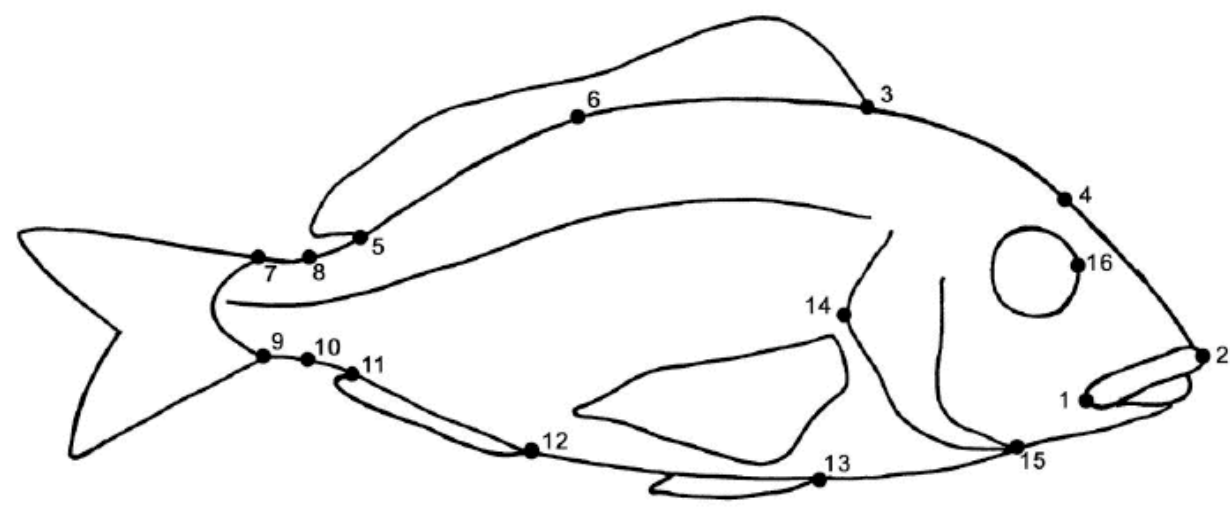

Fig. (1). Morphometric landmark locations for P. laniarius.

and marine systems, such as isolation or low species richness that are more common in freshwater systems. Or it may be the result of a lack of investigation of non-sexual variation in intraspecific fish morphology in marine systems.

We tested for non-sexual intraspecific shape variation in two common South African marine fishes used for human consumption, Pterogymnus laniarius (i.e., panga), and Argyrosomus inodorus (silver kob). These are sought after species that are caught in large numbers off the coast of South Africa. We quantified shape variation within populations of these two marine species and compared it to patterns of morphological variation commonly associated with the three environmental gradients described above.

\section{METHODS}

To quantify shape variation, we used digital photographs of $P$. laniarius and $A$. inodorus caught by commercial fishermen in a small-scale artisanal fishery in South Africa over a two month period. All fish were caught within about a 20 $\mathrm{km}$ radius from the East London Harbor in Eastern Cape, South Africa. We assume, based on the relatively close proximity of the fishing that these samples do not represent geographically distinct subpopulations. Within this area, fishes may inhabit somewhat different habitats, but there do not appear to be any distinct barriers to fish movement. We obtained usable full body, lateral view photographs of $44 P$. laniarius and $41 \mathrm{~A}$. inodorus.

We used landmark based geometric morphometrics [25] to quantify the morphological differentiation between individuals of each species. We chose 16 landmarks for $P$. laniarius as follows: (1) posterior extension of the maxilla with mouth closed, (2) tip of nose, (3) anterior origin of dorsal fin, (4) dorsal outline halfway between the tip of nose and anterior origin of dorsal fin, (5) posterior insertion of dorsal fin, (6) dorsal outline halfway through dorsal fin, (7) dorsal origin of caudal fin, (8) dorsal outline halfway between the posterior insertion of dorsal fin and dorsal origin of caudal fin, (9) ventral origin of caudal fin, (10) ventral outline halfway between ventral origin of caudal fin and posterior insertion of anal fin, (11) posterior insertion of anal fin, (12) anterior origin of anal fin, (13) anterior origin of pelvic fin on ventral outline, (14) posterior most point on operculum, (15) juncture of the ventral edge of operculum with the ventral outline, and (16) anterior most point of the eye (Fig. 1). We treated landmarks 4, 6, 8, 10, and 16 as sliding semilandmarks. Sliding semilandmarks are used to define an outline where only variation in one dimension is important, such as the outline shape of a smooth surface. Sliding semilandmarks are placed at some interval between two other landmarks and then the semilandmark is mathematically "slid" or adjusted on one axis (the uninformative axis) to be at the same location for all individuals in the sample. However, variation in the other axis is retained uniquely for all individuals [26].

We chose16 landmarks for A. inodorus as follows: (1) tip of nose, (2) posterior extension of maxilla with mouth closed, (3) juncture of ventral edge of operculum with the ventral outline, (4) anterior origin of pelvic fin on ventral outline, (5) anterior origin of anal fin, (6) ventral origin of caudal fin, (7) dorsal origin of caudal fin, (8) posterior insertion of dorsal fin, (9) anterior origin of dorsal fin, (10) anterior most point of the eye, (11) posterior most point of operculum, (12) ventral outline between anterior origin of pelvic fin and anterior origin of anal fin, (13) ventral outline between anterior origin of anal fin and ventral origin of caudal fin, (14) dorsal outline halfway through dorsal fin, (15) posterior most point of head on dorsal outline, and (16) dorsal outline halfway between posterior most point of head and tip of nose (Fig. 2). We treated landmarks 10, 12, 13, 14, 15, and 16 as sliding semilandmarks.

We used the "unbend" function in tpsUtil [F. James Rohlf, http://life.bio.sunysb.edu/morph/index.html] to eliminate variation in shape resulting from bendiness in the caudal region. We used routines in tpsRelW [F. James Rohlf, http://life.bio.sunysb.edu/morph/index.html] to superimpose landmarks and to create shape variables in the form of partial warps ( $\mathbf{W}$ matrix, or weight matrix), and then to summarize those in the form of relative warps. Relative warps allow visualization of a large proportion of shape variation in fewer dimensions. We characterized and inspected shape variation along the first two major axes of shape variation (relative warp 1 and relative warp 2) which accounted for $47.8 \%$ of the variation in P. laniarius and $67.0 \%$ of the variation in $A$. inodorus. We used thin-plate spline representations of observed shape variation for visual illustration [27]. 


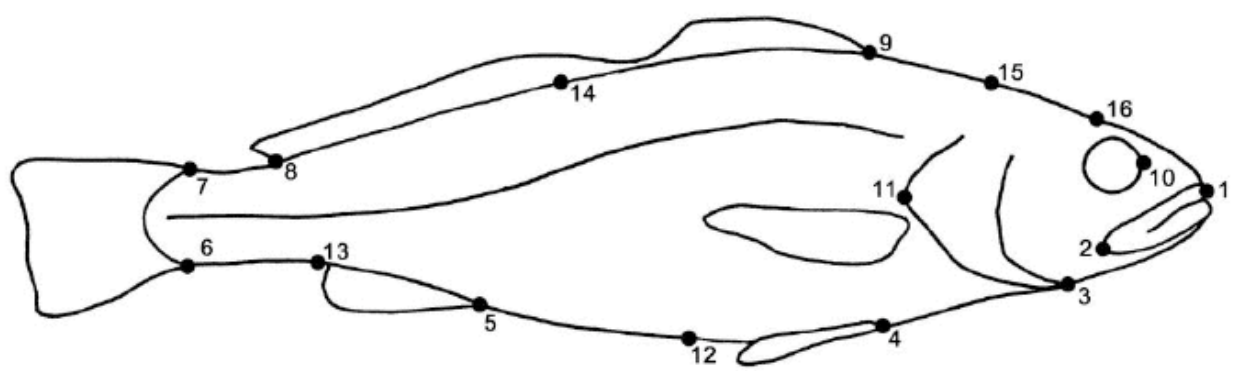

Fig. (2). Morphometric landmark locations for A. inodorus.
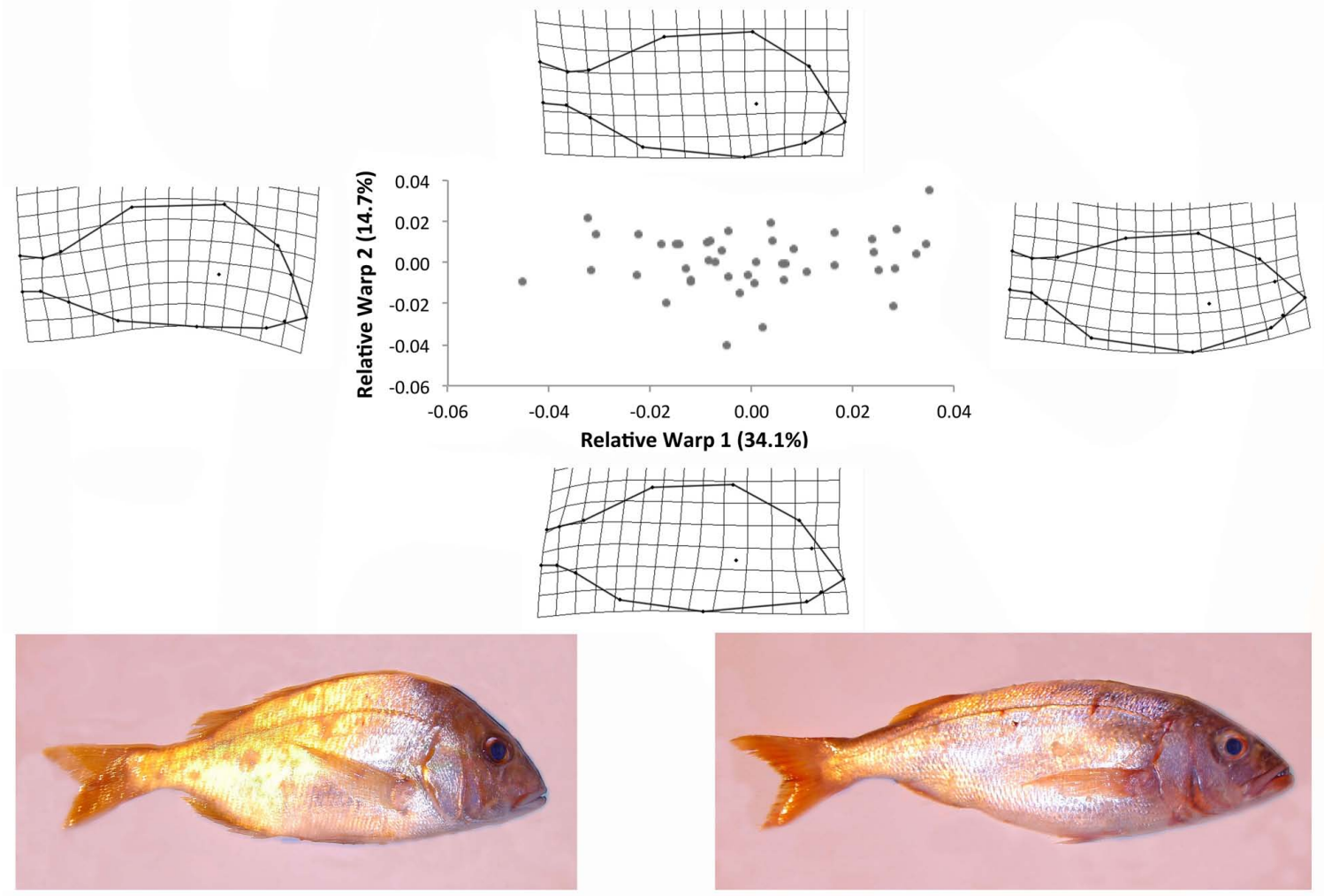

Fig. (3). Location of individual $P$. laniarius on relative warps 1 and 2, with thin plate splines showing visualizations of the shape change associated with each axis. For clarity, shape change was magnified two times. Photos show examples of the two extreme morphotypes from the samples used in the analysis.

We tested for sexual dimorphism in both species with multivariate analysis of covariance (MANCOVA) in a mixed model design [28]. Shape, as measured by the first twelve relative warps (includes $95 \%$ of variation in $P$. laniarius, and $97 \%$ of variation in $A$. inodorus), was the response variable. Sex was considered a fixed effect in the model and centroid size (i.e., a multivariate measure of body size) was used as a covariate. In a multivariate mixed model design, relative warps are treated as repeated measures within individuals, thus individual is treated as a random variable in the analysis. Analysis was done with the MIXED procedure in SAS (SAS Enterprise Guide v. 4.3, SAS Institute Inc., Cary, NC, USA) [29, 30].

\section{RESULTS}

In $P$. laniarius the first major axis of shape variation (relative warp 1) accounts for $33.4 \%$ of the total variation. It describes a change from an upturned head and mouth, low dorsal hump, and shallower more fusiform body shape to a downturned head and mouth, higher dorsal hump, and deeper more robust body shape. The second major axis of shape variation (relative warp 2) which accounts for $14.4 \%$ of the total variation describes a flattening and stretching of the head and trunk (Fig. 3).

In $A$. inodorus the first major axis of shape variation (relative warp 1) accounts for $55.6 \%$ of the total variation. Similar to $P$. laniarius it describes a change from an upturned head and mouth, low dorsal hump, and slender fusiform body shape to a downturned head and mouth, higher dorsal hump, and a deeper more robust body shape. The second major axis of shape variation (relative warp 2) accounts for $11.3 \%$ of the total variation and shows a lengthening and flattening of the head region (Fig. 4). 

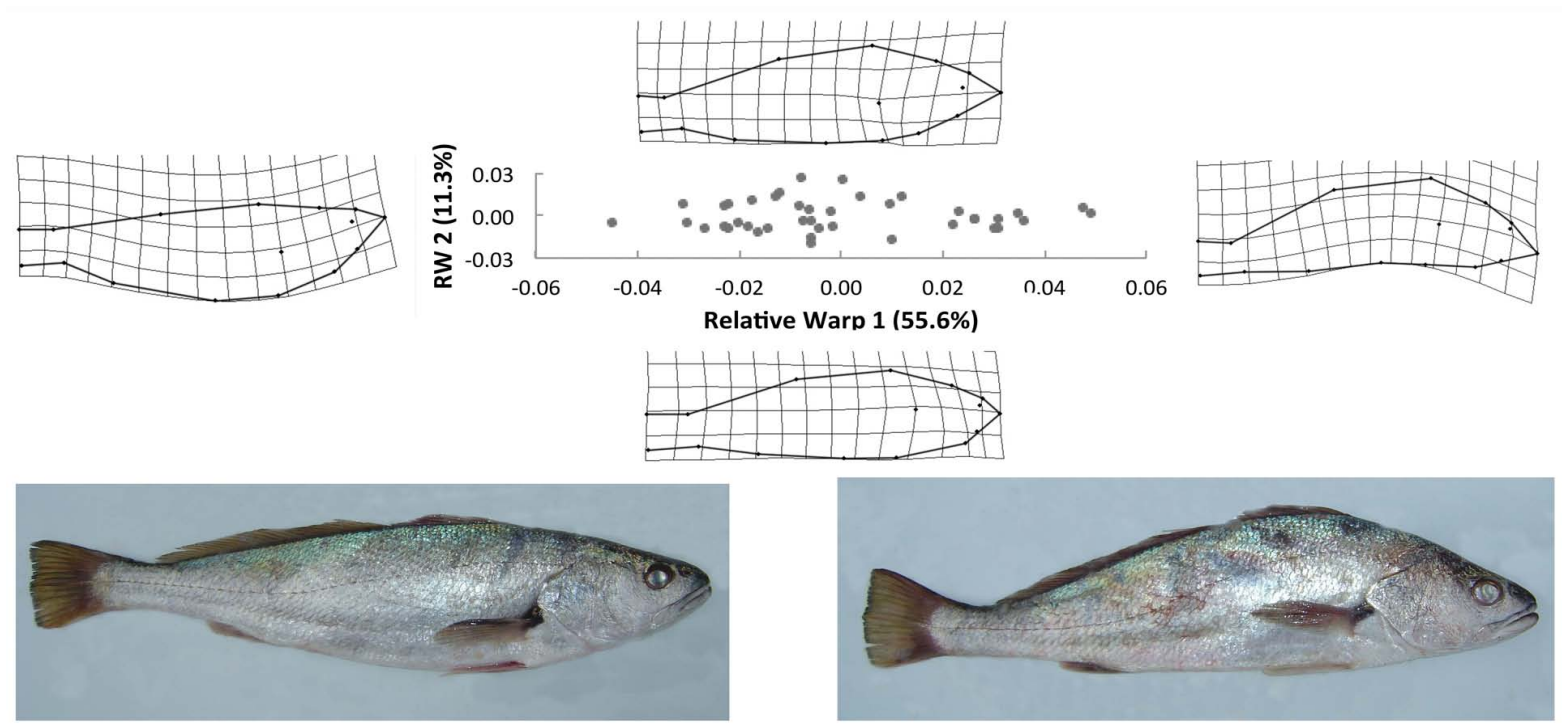

Fig. (4). Location of individual A.inodorus on relative warps 1 and 2, with thin plate splines showing visualizations of the shape change associated with each axis. For clarity, shape change was magnified two times. Photos show examples of the two extreme morphotypes from samples used in the analysis.

Neither species exhibited significant sexual dimorphism in shape $\left(P\right.$. laniarius, $\mathrm{F}_{11,184}=0.81, \mathrm{P}=0.63 ;$ A. inodorus, $\left.\mathrm{F}_{11,170}=1.20, \mathrm{P}=0.29\right)$. In addition, centroid size was not a significant predictor of shape in either species ( $P$. laniarius, $\mathrm{F}_{11,184}=1.53, \mathrm{P}=0.12 ;$ A inodorus, $\left.\mathrm{F}_{11,170}=0.85, \mathrm{P}=0.59\right)$.

\section{DISCUSSION}

Both species we investigated showed a substantial range of non-sexual morphological variation comparable to that documented in other fish species [17-20]. This result was somewhat surprising because intraspecific morphological variation is not well documented and often not anticipated among marine fishes. One reason that it is not anticipated in marine systems is that it is assumed that there are fewer barriers to gene flow than in freshwater systems [31, 32]. Without physical barriers to gene flow there is less opportunity for local adaptation to occur which could result in more homogenous populations. Another reason intraspecific morphological variation is often not anticipated is because marine systems often have more diverse communities than freshwater systems [32]. With this greater diversity there are fewer opportunities for ecological variation. Both $P$. laniarius and $A$. inodorus are common marine fishes with no characteristics setting them apart as more likely than other species to exhibit such morphological variation. If intraspecific morphological variation can be found in these common marine fishes, it is likely that it exists in other marine fishes. The lack of documentation of such variation in marine fishes may be the result of a lack of investigation rather than fundamental differences between freshwater and marine systems. This may be a fruitful area of future research.

The morphological variation seen in P. laniarius and $A$. inodorus is similar to variation seen in freshwater populations associated with the benthic-pelagic feeding niche continuum. The dominant axis of shape variation (first relative warp) for both species describes a change from a more slender body with an upturned head and mouth and a low dorsal hump to a more robust body with a downturned head and mouth and a higher dorsal hump. Classic freshwater examples that exhibit morphological variation associated with the benthic-pelagic gradient such as whitefish, threespine sticklebacks, and brook charr show these same patterns $[1,6,17$, 18]. For variation to occur along the benthic-pelagic gradient there must be different resources available in the benthic and pelagic zones that can be better exploited by individuals with different morphologies. These ecological factors that promote variation along the benthic-pelagic gradient are present in both freshwater and marine systems so it is not surprising that the variation we saw in P. laniarius and $A$. inodorus fits with this gradient.

An alternative explanation for this shape variation is a response to predation intensity by gape-limited predators. Similar to the example of Eurasian perch (Perca fluviatilis) [12], deeper body shape as seen in both species, may decrease mortality from gape-limited predators. However, the position of the mouth (especially in P. laniarius), and the lack of variation in the caudal peduncle region does not correspond to the pattern expected from a predation gradient [11]. In addition, it seems unlikely that the range of variation from low to high predation intensity would exist in marine systems within small geographic areas.

Fundamentally, adaptation to predation intensity or water velocity requires some form of isolation and allopatry on some scale that will create alternative selective environments. Variation in feeding niche, on the other hand, is based on behavior of the individual, and as such, can arise under sympatric conditions. Variation along the benthic-pelagic continuum seems likely to occur in marine systems; whereas, variation with predation intensity and water velocity seem unlikely to occur in marine systems. Thus, the lack of documentation of intraspecific morphological variation in marine systems along the benthic-pelagic axis is likely due to a lack of investigation. However, lack of documentation of morphological variation associated with environmental variation 
in predation or water velocity may be the result of fundamental differences between freshwater and marine systems.

We know that morphological variation occurs in $P$. laniarius and A. inodorus, however, we do not know whether this variation is a heritable, genetically based trait or whether it is due to phenotypic plasticity. There are a variety of factors that can induce non-genetically based phenotypic variation in fishes $[33,34]$. None of these factors have been experimentally tested with $P$. laniarius or $A$. inodorus, so it cannot yet be determined whether the morphological variation observed is heritable or a result of phenotypic plasticity. More research on intraspecific morphological variation among marine fishes is necessary to determine the genetic basis for such variation.

\section{CONFLICT OF INTEREST}

The authors confirm that this article content has no conflicts of interest.

\section{ACKNOWLEDGEMENTS}

We thank Timothy Steflik and Matthew Schaeffer for photographs and landmark acquisition. We also thank the Brigham Young University Biology Department for support.

\section{REFERENCES}

[1] Robinson BW, Wilson DS. Character release and displacement in fishes: a neglected literature. Am Nat 1994; 144: 596-627.

[2] Parker AD, Stepien CA, Sepulveda-Villet OJ, Ruehl CB, Uzarski DG. Interplay of morphology, habitat, resource use, and genetic relationships in young yellow perch. Trans Am Fish Soc 2009; 138: 899-914.

[3] Parker GA. The evolution of sexual size dimorphism in fish. J Fish Biol 1992; 41: 1-20.

[4] Breder CM, Rosen DE. Modes of Reproduction in Fishes. Garden City, New York: Natural History Press 1996

[5] Ehlinger TJ, Wilson DS. Complex foraging polymorphism in bluegill sunfish. Proc Natl Acad Sci USA 1988; 85: 1878-82.

[6] Schluter D, McPhail JD. Ecological character displacement and speciation in sticklebacks. Am Nat 1992; 140: 85-108.

[7] Webster MM, Atton N, Hart PJB, Ward AJW. Habitat-specific morphological variation among threespine sticklebacks (Gasterosterus aculeatus) within a drainage basin. PLoS One 2011; 6: 1-10.

[8] Spoljaric MA, Reimchen TE. Habitat-specific trends in ontogeny of body shape in stickleback from coastal archipelago: potential for rapid shifts in colonizing populations. J Morphology 2011; 272: $590-7$.

[9] Collin H, Fumagalli L. Evidence for morphological and adaptive genetic divergence between lake and stream habitats in European minnows (Phoxinus phoxinus, cyprinidae). Mol Ecol 2011; 20: 4490-502.

[10] Moles MD, Robinson BW, Johnston TA. Morphological and trophic differentiation of growth morphotypes of walleye (Sander vitreus) from Lake Winnipeg, Canada. Can J Zool 2010; 88: 95060.

[11] Langerhans RB, Layman CA, Shokrollahi AM, DeWitt TJ. Predator-driven phenotypic diversification in Gambusia affinis. Evolution 2004; 58: 2305-18.
[12] Eklov P, Svanback R. Risk influences adaptive morphological variation in fish populations. Am Nat 2006; 167: 440-52.

[13] Langerhans RB. Predictability of phenotypic differentiation across flow regimes in fishes. Integr Comp Biol 2008; 48: 750-68.

[14] Imre I, McLaughlin RL, Noakes DLG. Phenotypic plasticity in brook char: changes in caudal fin induced by water flow. J Fish Biol 2002; 61: 1171-81.

[15] Schluter D, McPhail JD. Character displacement and replicate adaptive radiation. Trends Ecol Evol 1993; 8: 197-200.

[16] Bittner D, Excoffier L, Largiader CR. Patterns of morphological changes and hybridization between sympatric whitefish morphs (Coregonus spp.) in a Swiss lake: a role for eutrophication? Mol Ecol 2010; 19: 2152-67.

[17] Amnudsen P, Knudsen R, Klementsen, Kristoffersen. Resource competition and interactive segregation between sympatric whitefish morphs. Ann Zool Fennici 2004; 41:301-7.

[18] Dynes J, Magnan P, Bernatchez L, Rodriguez MA. Genetic and morphological variation between two forms of lacustrine brook char. J Fish Biol 1999; 54: 955-72.

[19] Hegrenes S. Diet-induced phenotypic plasticity of feeding morphology in the orangespotted sunfish, Lepomis humilis. Ecol Freshw Fish 2001; 10: 35-42.

[20] Matthews B, Marchinko KB, Bolnick DI, Mazumder A. Specialization of trophic position and habitat use by sticklebacks in an adaptive radiation. Ecology 2010; 91:1025-34.

[21] Lindsey CC. Stocks are chameleons: plasticity in gill rakers of coregonid fishes. Can J Fish Aquat Sci 1981; 38: 1497-506.

[22] Hjelm J, Svanback R, Bystrom P, Persson L, Wahlstrom E. Dietdependent body morphology and ontogenetic reaction norms in Eurasian perch. OIKOS 2001; 95: 311-23.

[23] Snorrason SS, Skulason S, Jonsson B, et al. Trophic specialization in arctic charr Salvelinus alpinus (pisces; salmonidae): morphological divergence and ontogenetic niche shifts. Biol J Linnean Soc 1994; 52: 1-18.

[24] Garduno-Paz MV, Adams CE. Discrete prey availability promotes foraging segregation and early divergence in Arctic charr, Salvelinus alpinus. Hydrobiologia 2010; 650: 15-26.

[25] Rohlf FJ, Marcus LF. A revolution in morphometrics. Trends Ecol Evol 1993; 8:129-132.

[26] Bookstein FL, Schafer K, Prossinger H, et al. Comparing frontal cranial profiles in archaic and modern Homo by morphometric analysis. Anat Rec 1999; 257: 217-24.

[27] Adams DC, Rohlf FJ, Slice DE. Geometric morphometrics: ten years of progress following the 'Revolution'. It J Zool 2002; 71: 5-16.

[28] Littell RC, Milliken GA, Stroup WW, Wolfinger RD. SAS System for Mixed Models. Cary, North Carolina: SAS Institute Inc 1996

[29] Hassell EMA, Meyers PJ, Billman EJ, Rasmussen JE, Belk MC. Ontogeny and sex alter the effect of predation on body shape in a livebearing fish: sexual dimorphism, parallelism, and costs of reproduction. Ecol Evol 2012; 2: 1738-46.

[30] Wesner JS, Billman EJ, Meier A, Belk MC. Morphological convergence during pregnancy among predator and non-predator populations of the livebearing fish Brachyrhaphis rhabdophora (Teleostei: Poecilidae). Biol J Linnean Soc 2011; 104: 386-92.

[31] Ingram T. Speciation along a depth gradient in a marine adaptive radiation. Proc R Soc 2010; 278:613-8.

[32] Palumbi SR. Genetic-divergence, reproductive isolation, and marine speciation. Ann Rev Ecol Syst 1994; 25: 547-72.

[33] Belk MC, Benson LJ, Rasmussen J, Peck SL. Hatchery-induced morphological variation in an endangered fish: a challenge for hatchery-based recovery efforts. Can J Fish Aquat Sci 2008; 65: 401-8.

[34] Robinson BW, Wilson DS. Experimentally induced morphological diversity in Trinidadian guppies (Poecilia reticulata). Copeia 1995; (2): 294-305. 